\title{
EFERTILIZER APPLICATOR EVALUATION USING THE RESPONSE SURFACE METHODOLOGY
}

\author{
Ismail Z. Ebrahim*
}

\begin{abstract}
During the last decade, a great deal of attention gave to reclaim new lands (desert lands) and grow these lands by vegetable crops whereas these crops are considered to be high income in short rotation. Further, increase in vegetables production by increasing the yield per unit area is required by controlling the amount of fertilizer application. The fertilizer machine used in experiments is a banded type applicator consisting of a fertilizing hopper, metering device, agitator unit, fertilizer tubes, forming profile unit and transmission system. Response Surface Methodology (RSM) was employed to optimize the operating (peripheral speed of the auger, the gate area levels and auger volume) and constructional-related variables (fertilizer application rate). The design in this study is a Central Composite Design "CCD" by which it studied the influence of three factors in 15 runs at which three levels for each independent variable. These levels were coded "-1"; "0" and "+1" respectively. The design is to be run in a single block, to provide protection against the effects of turning variables, the order of experimental has been fully randomized. The optimum levels of the auger peripheral speed " $A_{s}$ ", auger volumetric capacity " $A_{v}$ " and gate area " $G_{a}{ }^{\prime}$ for three different fertilizer types are very close and they are in good agreement. For Super phosphate as example there were $5 \mathrm{~m} / \mathrm{s}, 45 \mathrm{~cm}^{3}$ and $40 \mathrm{~cm}^{2}$ respectively. The highest value of discharge rate for Urea is 159.6 $\mathrm{kg} / \mathrm{h}$ that obtained at orifice gate area of $48 \mathrm{~cm}^{2}$, auger volume of $50 \mathrm{~cm}^{3}$ and feeding shaft rotational speed of $10 \mathrm{~m} / \mathrm{s}$. Increasing the gate area from 16 to $48 \mathrm{~cm}^{2}$ increases the volumetric efficiency from $64.9 \%$ to $79.0 \%$; from 68.6 to 79.7, and from $39.4 \%$ to $51.2 \%$ for Urea, Nitrate and Superphosphate respectively.
\end{abstract}

Keywords: Response Surface Methodology (RSM), band spreader, application rate, fertilizing hopper, metering device, agitator unit, forming profile unit, auger shaft speed, auger volume, gate area.

*Prof. Dr of power technology and farm machinery, Agric. Eng. Dept., Mansoura University. ismailze221@ mans.edu.eg 


\section{INTRODUCTION}

Tn Egypt, the agricultural land can be divided in to two wide types, namely: the old land (Delta land) around the Nile River and the New Land (desert land). To reclaiming New Lands and growing these lands by vegetable crops is the main goal, whereas, these crops are considered to be high income in short rotation. One of the major problems facing this aim in Egypt as well as other parts of world is the appropriate fertilization including program and system of addition. The mineral fertilizers are generally applied as broadcast. The drawbacks with broadcast application are, stimulate weed growth and fertilizer may come in contact with a large volume of soil and are likely to be fixed, there for, the crop does not derive full benefit of fertilizer, finally for application of phosphoric fertilizer as Super-phosphates are less mobile. Broadcast application will result in unavailability to roots. Consequently, as all the nutrients fertilizer are applied at the time of sowing or planting, it is a good practice to apply the fertilizer as placement, to decrease fertilizer looser by drainage water and increased the total nutrients in soil profile. The advantages of fertilizer placement are, stimulates early growth of seedlings, early root development will be rapid and extensive and plant growth will be stimulated. Kathleen (1998) and Neddermeijer et. al (2000) stated that Super-phosphate fertilizer in wheat is conventionally applied by broadcast method before sowing crop. This is a wasteful method of fertilizer application as only (15-25\%) of the applied Superphosphate is utilized by wheat crop. They also revealed that currently seed cum fertilizer drill place fertilizer either too far from the seed or in direct contact with it. In the former case, fertilizer use efficiency is hampered and in latter situation, relatively high rate of ammoniated Super-phosphate fertilizer affects the seed germination and crop yield. To solve mentioned problem the seed cum fertilizer is developed to place fertilizer $5 \mathrm{~cm}$ away and $5 \mathrm{~cm}$ deeper that the seed. Thus is saving $50 \%$ of Super-phosphate fertilizers and get benefit of $10 \%$ more grain yield.

Persson et al. (1999) investigated the technical solutions for variable rate fertilization. The aim of variable rate fertilizer application is to fulfill local requirements in the field to optimize the production for quantity or quality reasons. The choice of spreading technique and working width 
influences the possibilities of performing variable rate fertilizer application. Based on two-dimensional measurement of distribution patterns from different fertilizer distributors at different working widths and application rates, the overall distribution pattern may be calculated for fields in which variable rate is intended. Calculations that have been carried out based on distribution patterns from common types of mineral fertilizer distributors show that the bigger the spatial variability in the field, the smaller the working width that should be used. While, Reumers et al. (2003) explained the experimental characterization of the tangential and cylindrical fertilizer distribution pattern from a spinning disc. Traditionally the performance of centrifugal spreaders is evaluated in spreading halls by measuring fertilizer distribution patterns in standardized tests. Alternative distribution patterns can be measured with compact devices that intercept the particle flow immediately after leaving the spinning disc. An experimental facility was built which allowed the measurement of the tangential, as well as the cylindrical distribution of the particle flow at the disc edge. A number of experiments were carried out, using one type of centrifugal spreader with a conical disc. The influences of vane length, mass flow rate, and particle size and fertilizer type on both the tangential and the cylindrical distribution patterns have been investigated. The results show that flows of particles with a larger mean diameter achieve a higher velocity on the disc, causing the distribution patterns to shift to lower angular positions. Furthermore, it is concluded that a smaller average particle size leads to a higher mass discharge flow rate from the hopper. In addition, a shift of the cylindrical distribution to a lower vertical position is observed when the mass flow rate increases.

William et al. (2004) indicated that granular fertilizer applications through variable-rate technology (VRT) for Florida citrus can be implemented through either real time sensing, GIS-map based control, or both. Evaluations were undertaken to establish the response of these techniques with two dry fertilizer units with different hydraulic configurations. A test program using ASAE S341.3 has been established for standardized conditions. Additionally, field trials were undertaken to ascertain fertilizer distribution under grove conditions. In these field 
trials, both spinner disc and pneumatic discharge units were evaluated. Fertilizer distribution under grove conditions yielded distributions quite different from the Gaussian distributions found in open-field standardized tests. Coefficients of variation in tray distribution tests across the fertilizer swath were lower; $41.0 \%$ for grove condition versus $93.9 \%$ in open field results when comparing the same spreader unit. Grove application rates for three commercial spreaders were determined by under-tree tray collection of fertilizer and varied by $7.7 \%$ from the controller set point values. For both units, delay times (on-off) was 30\% less than the off-on transition.

Kaplan et al. (1999) aimed to evaluate unevenness of fertilizer distribution and determination of the application rate. The relationship between the unevenness of the fertilizer distribution and the optimum application rate was studied using experimental data and different response function models. A universal formula derived from this study can be used to determine the relative loss of fertilizer for different models of the response function. It was shown that the loss of fertilizer for many cases can be accounted for the use the quadratic model. The formulae to correct the application rate for the given unevenness were obtained. Liu et al. (1998) developed a fertilizer distributor, which applies chemical fertilizers into the subsoil, where phosphorus and calcium, are mixed. In addition, based on root density distribution, a technique developed in which the fertilizer placed more densely in the upper layer than in the lower layer within the 200-600 mm depth of the subsoil. When both granular and powder fertilizers were applied at the rear of the first or second plow body, fertilizers reached the bottom layer with soil mixing by the plow bodies, and fertilizer distribution was greatest in the lower layer of the subsoil. When fertilizers applied at the side of the third plow body, an improved distribution obtained, but was not distributed over the entire operating width $(300 \mathrm{~mm})$, but concentrated more around the side of the third plough body. When fertilizer applied both at the rear and at the side of the third plough body, the desired distribution obtained, and the distribution density decreased linearly with tilled soil depth. 
The conveying fertilizer in horizontal auger device faces many factors affecting the performance of application fertilizer rate (Ismail-2007). The lever control in the fertilizer tank bottom and the amount of feeding device parameters are considers as the main static factors influence of the fertilizer rate performance. While, the application rate of metering device, metering device efficiency and felid efficiency for Super-phosphate $(15 \%)$, Nitrate $(33.5 \%)$ and Urea $(46.5 \%)$ are considers as the main dependent variables used in developing response surface functions.

Therefore, this investigation aimed to use the response surface methodology (RSM) that select and evaluate a suitable operation condition realizing the optimum fertilizer application rate and machine volumetric efficiency.

\section{MATERIALS AND METHODS}

In the experiments, the banded type fertilizer machine is consisting of a fertilizing hopper, metering device, agitator unit, fertilizer tubes and transmission system and forming profile unit (Fig. 1). The ground wheel of the proposed fertilizer unit driven the auger shaft that located inside the hopper near the bottom carries agitator to keep the flow of material constant (Fig. 2). A slide gate used to control the openings and to shut-off flow during turn around. In fertilizer prototype machine, three hoppers have a square cross section at the top of $360 \times 360 \mathrm{~mm}$, and trapezoidal at the bottom. In order to facilitate the flow of materials to slide down along the hopper walls, the latter must be inclined under a relevantly large angle $60^{\circ}$ larger than the friction angle of the fertilizers against the hopper walls. Each hopper has a capacity of $35 \mathrm{~kg}$ of fertilizer (Fig. 3-A). The horizontal shaft located near the bottom of the fertilizer hopper. The shaft is operated by a transmission system that powered by the ground wheel. Transmission system as shown in Fig. (3-B) has two functions for driving metric device from land wheel, and for changing the auger shaft rotating speed to obtain different application fertilizer rates, $\mathrm{kg} /$ feddan (one feddan $=0.42$ hectare). The fertilizer is delivered through a rubber tube on soil surface and covered by soil that formed by the profile maker unit. 
In lab, the plastic bags are provided on fertilizer application tubes to determine the machine performance. The measurement of fertilizer amount was carried out at a duration time of $15 \mathrm{~min}$ approximately for each run. The machine land wheel was mounted above the lab surface as closely as possible to permit the fertilizer ingathering in plastic bags and it is driven by an electric motor.

One of the most important factors affecting the application fertilizers rate is the auger volumetric capacity. As a statistical and mathematical technique, Response Surface Methodology (RSM) was employed to optimize the operating (peripheral) speed of the auger and the gate area levels and constructional-related variables (auger volume). The RSM designs are not primarily used for understanding the mechanism of the underlying system and assessing treatment main effects and interactions, but to determine, within some limits, the optimum operating conditions of system (Kathleen, 2004). It is less laborious and time-consuming that other approaches and is an effective technique for optimizing complex processes since it reduces the number of experiments needed to evaluate multiple parameters and their interactions (lee et al., 2006).

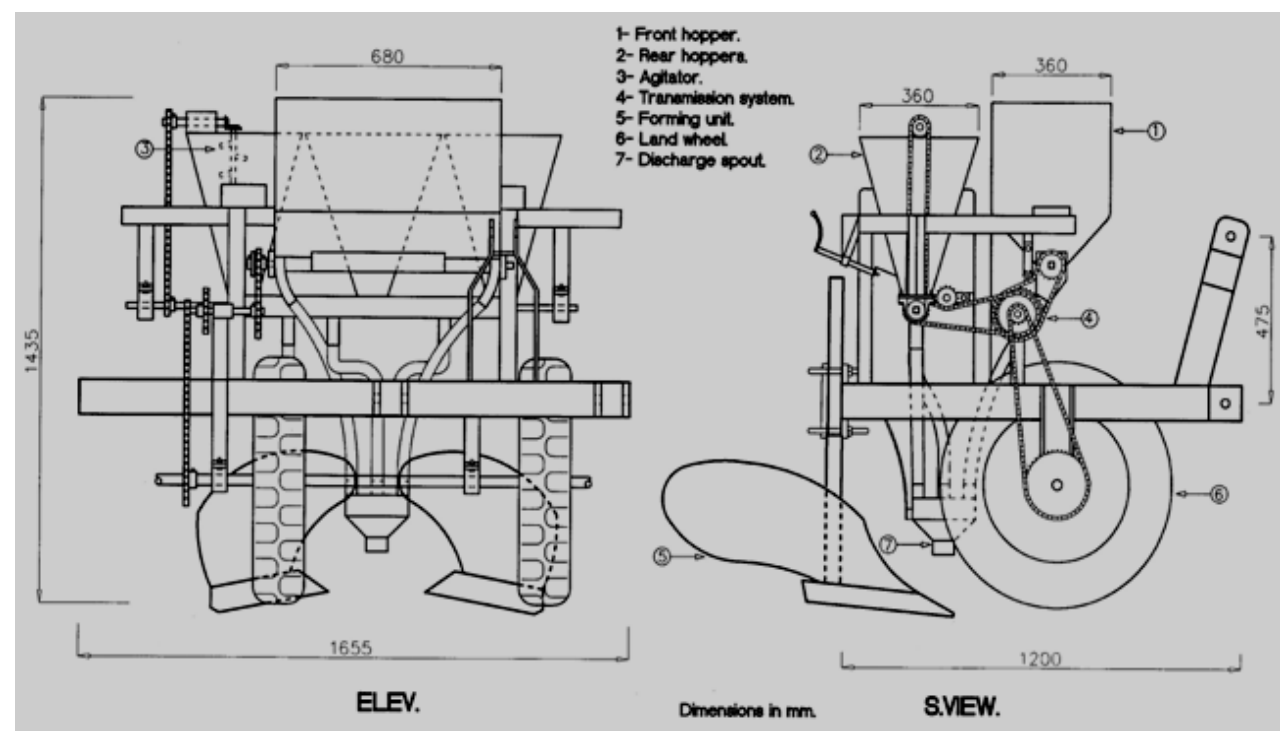

Fig.1-A: The layout of fertilizer 


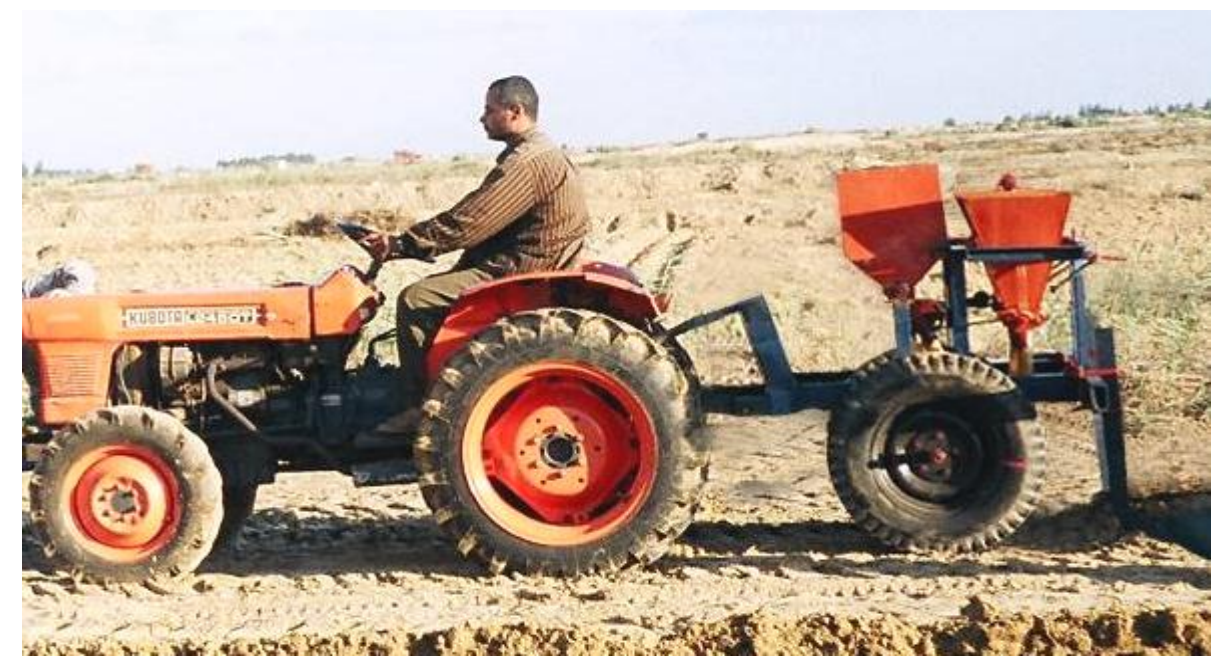

Fig. 1-B: The photograph of fertilizer prototype

Fig. 1: The prototype of Fertilizer

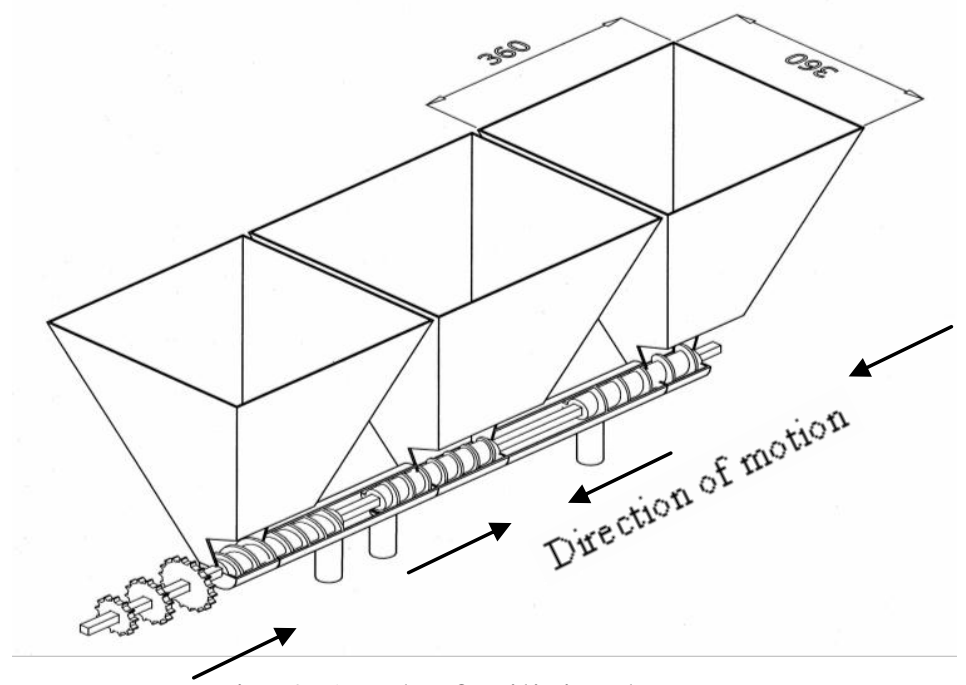

Fig. 2-A: The fertilizing hoppers

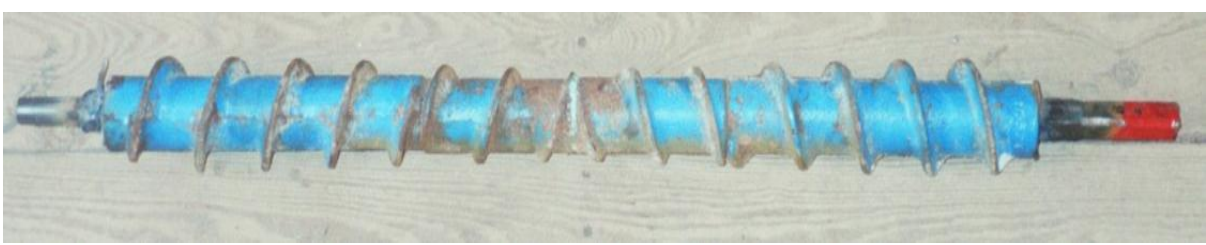

Fig. 2-B: The fertilizing auger shaft 


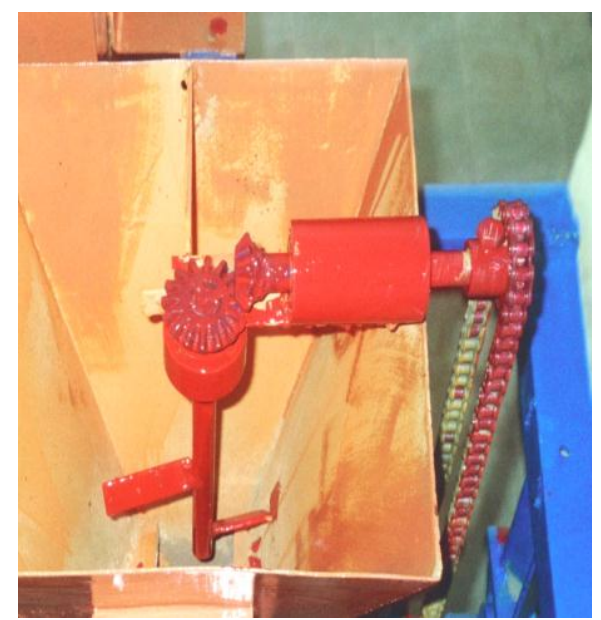

Fig. 3-A: The transmissions to

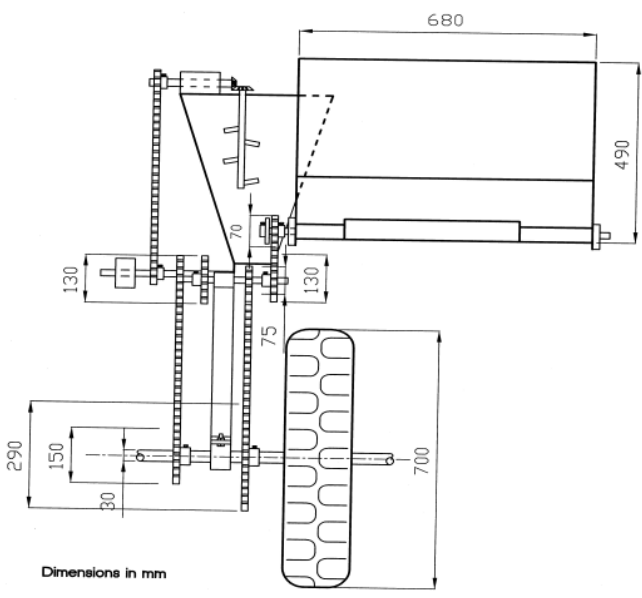

Fig. 3-B: The transmissions system vertical agitator

The response surface problem usually centers on an interest in some response "Y", which is a function of "Y" independent variables $\zeta_{1}, \zeta_{2}, \zeta_{3} \ldots . ., \zeta_{k}$, that is,

$$
Y=f\left(\zeta_{1}, \zeta_{2}, \ldots \ldots \ldots \ldots \zeta_{k}\right)+\varepsilon
$$

and response surface can take the different forms according to the function types of response and usually response function is defined in the quadratic polynomial form as follows:

$$
Y=\beta_{0}+\sum^{k} \beta_{i} \chi_{i}+\sum^{k} \beta_{i i} \chi_{i}^{2}+\sum \sum^{k} \beta_{i i} \chi_{i} \chi_{i}+\varepsilon
$$

Where $\mathrm{Y}$ is the response; $\beta_{\mathrm{o}}$ is the intercept; $\beta_{\mathrm{j}} ; \beta_{\mathrm{jj}} ; \beta_{\mathrm{ij}}$ are the regression coefficients; $\chi_{\mathrm{j}} ; \chi_{\mathrm{i}}$ are the coded variables; and $\varepsilon$ is the error. The coding of independent variables into $\chi_{i}$ is expressed by the following equation:

$$
\chi_{\mathrm{i}}=\left(\zeta-\zeta^{*}\right) / \mathrm{ds}
$$

Where " $\zeta$ " is the actual value in original units; " $\zeta *$ " is the mean value (center point); and " $\mathrm{d}_{\mathrm{s}}$ " is the step value. The determination of center point for each independent variable was based on field conditions and the pre-experimental in lab on the three types of fertilizer used (Superphosphate-15\%, Nitrate-33.5\% and Urea-46.5\%). The special care has to be given for the selection of centre point as well as the minimum and maximum levels in order to construct polynomial functions form which the optimum levels of the independent variables are to be 
calculated. The design in this study is a Central Composite Design "CCD" by which it studied the influence of three factors in 15 runs at which three levels for each independent variable. These levels were coded "-1"; " 0 " and "+1" respectively. The design is to be run in a single block, to provide protection against the effects of turning variables, the order of experimental has been fully randomized.

The centre point in this design is coded as zero and as the volumetric capacity of auger was chosen to be $36 \mathrm{~cm}^{3}$. A step value of $14 \mathrm{~cm}^{3}$ was selected and as a result of this study, the selected auger volume dimension for the fertilizer auger becomes $22 \mathrm{~cm}^{3}$ and $50 \mathrm{~cm}^{3}$. To verify the above aim, the metering device is made of three augers are different in pitches length and screw diameter (screw flight diameter of 5.3, 6.0 and $5.8 \mathrm{~cm}$, screw shaft diameters are 4.05; 4.11 and $3.93 \mathrm{~cm}$ and pitch length $\left(\mathrm{P}_{\mathrm{L}}\right)$ of $2.4,2.4$ and $3.5 \mathrm{~cm}$ respectively). The three different augers are located, one by one on the feeding shaft hoppers as shown in Fig. (2-A), which there are provided from the local manufacturing company of the farm machinery.

The prototype of fertilizer had a ground-driven wheel that transfers the motion to the fertilizer auger with a combination of gears available (Fig.3-B). It was operated at three different peripheral speeds of 5.0, 7.5 and $10.0 \mathrm{~ms}^{-1}$. The peripheral speed center point of $7.5 \mathrm{~ms}^{-1}$ for the fertilizer auger corresponds to $4.2 \mathrm{kmh}^{-1}$ of machine traveling speed. The selection of the peripheral speed of the auger was achieved by considering the traveling speed of the fertilizer machine in the field. This relation can be found as the theoretical relative to the agronomy requirement and the types of planting crop (Ismail, 2009). The amount of fertilizer flow rates were regulated by controlling the gate area. There are three slide control gates, which are fixed on the hopper sides to control the amount of flow from the hopper and auger chambers, with the total cross section of the orifice gates is $150 \times 80 \mathrm{~mm}$. the gate orifice level was centered at $32 \mathrm{~cm}^{2}$ while the other levels were calculated based on the CCD principles at a step value of $16 \mathrm{~cm}^{2}$ of the projected orifice area. Table 1 gives a list of independent variables and the coded factor levels. 
Each operating condition was established carefully and the rate of application flow $\left(\mathrm{A}_{\mathrm{R}}\right)$ was measured in terms of $\mathrm{kg} / \mathrm{fed}$ as:

$$
A_{R}=\frac{4200 \times D}{2 \pi r n w}
$$

Where, " $\mathrm{D}$ " is the discharge rate $(\mathrm{kg} / \mathrm{min})$, " $\mathrm{r}$ " is a land wheel radius (meter), " $\mathrm{n}$ " is revolution number of land wheel per minute (rpm), "w" is operating width (m) and 4200 is the Egyptian feddan area. Each test was replicated three times.

Table 1: Coded level for independent variables used in developing response surface functions

\begin{tabular}{|l|c|c|c|c|}
\hline \multirow{2}{*}{ Independent variables } & \multirow{2}{*}{ code } & \multicolumn{3}{|c|}{ Coded level } \\
\cline { 3 - 5 } & & -1 & 0 & +1 \\
\hline Auger shaft speed, $\mathrm{m} / \mathrm{s}$ & $\mathrm{A}_{\mathrm{s}}$ & 5.0 & 7.5 & 10 \\
\hline Auger volume, $\mathrm{cm}^{3}$ & $\mathrm{~A}_{\mathrm{v}}$ & 22 & 36 & 50 \\
\hline Gate area, $\mathrm{cm}^{2}$ & $\mathrm{G}_{\mathrm{a}}$ & 16 & 32 & 48 \\
\hline
\end{tabular}

The performance of fertilizer application was evaluated using measures based on those adopted by Fouda (2007). Generally, the discharge rate in terms of volume per unit time $\left(\mathrm{m}^{3} \mathrm{~min}^{-1}\right)$, It is expressed as $Q_{a}=\frac{D}{\rho}$. Where " $\mathrm{Q}_{\mathrm{a}}$ " is the actual volume capacity $\left(\mathrm{cm}^{3} \mathrm{~min}^{-1}\right)$; and " $\rho$ " is the bulk density of the material $\left(\mathrm{kg} \mathrm{cm}^{-3}\right)$. In reality, the actual capacity of an auger is consider less than the theoretical $\left(\mathrm{Q}_{\mathrm{th}}\right)$. Then the volumetric efficiency " $\eta_{v}$ " is defined as $\eta_{v}=\frac{Q_{a}}{Q_{t h}} \times 100$.

The measured of the discharge rate were entered into an Excel spreadsheet where each data set was split into different groups of the actual volume capacity and theoretical capacity " $\mathrm{Q}_{\mathrm{th}}$ " to determine the application flow rate for three types of fertilizer (Super phosphate, Nitrate and Urea). These types were selected as one of the famous varieties used in Egyptian farms and the physical properties of these varieties were shown in Table (2). The performance data were then transferred into a Minitab statistical package program for further analysis. All of the replications were used for the development of response surface function. The response surface functions were developed for each performance criteria. The functions developed were defined as full quadratic polynomials in Minitab, a statistical package program and stepwise procedure used for 
the selection of the variables as they enter the model in liner, interaction and quadratic form.

Table 2: the physical properties of the different fertilizers

\begin{tabular}{|l|c|c|c|c|c|c|}
\hline \multicolumn{1}{|c|}{ Name of fertilizer } & $\begin{array}{c}\text { Bulk density, } \\
\mathrm{g} / \mathrm{cm}^{3}\end{array}$ & $\begin{array}{c}\text { Angle of } \\
\text { repose }\end{array}$ & $\begin{array}{c}\text { Friction angle } \\
\text { against steel }\end{array}$ & $\begin{array}{c}\text { Form of } \\
\text { fertilizer }\end{array}$ & Hygroscopic & Remarks \\
\hline Super phosphate, $15 \%$ & $0.995 \pm 0.025$ & $44^{\circ} \pm 1.35$ & $30.5^{\circ} \pm 2.01$ & Powder & Low & Medium distribution \\
\hline Nitrate, $33.5 \%$ & $0.913 \pm 0.013$ & $33^{\circ} \pm 1.65$ & $28.5^{\circ} \pm 1.82$ & Granulated & Medium & Easy distribution \\
\hline Urea, $46.5 \%$ & $0.685 \pm 0.054$ & $28^{\circ} \pm 0.98$ & $19^{\circ} \pm 0.95$ & Spherical & High & Easy distribution \\
\hline
\end{tabular}

\section{RESULTS AND DISCUSSION}

\section{The application rate}

The experimental results carried out in the laboratory based on Center Composite Design "CCD" are given in Table 3. As can be seen the auger operated at $7.5 \mathrm{~ms}^{-1}$ peripheral speed, average volumetric capacity $50 \mathrm{~cm}^{3}$ and gate area of $48 \mathrm{~cm}^{2}$ gives a satisfactory results in terms of application rate $\left(A_{R}, k g / f e d\right)$. This result could be explained as the good selection of the ranges for the independent variables and their step values.

Table 3: General (CCD) with coded and un-coded independent variables and performance values

\begin{tabular}{|c|c|c|c|c|c|c|}
\hline \multirow{2}{*}{} & \multicolumn{3}{|c|}{ In depended variables } & \multicolumn{3}{c|}{ Depended variables $\left(\mathrm{A}_{\mathrm{R}}, \mathrm{kg} / \mathrm{fed}\right)$} \\
\cline { 2 - 7 } & $\begin{array}{c}\mathrm{X}_{1} \\
\left(\mathrm{~A}_{\mathrm{s}}, \mathrm{m} / \mathrm{s}\right)\end{array}$ & $\begin{array}{c}\mathrm{X}_{2} \\
\left(\mathrm{~A}, \mathrm{~cm}^{3}\right)\end{array}$ & $\begin{array}{c}\mathrm{X}_{3} \\
\left(\mathrm{G}, \mathrm{cm}^{2}\right)\end{array}$ & $\begin{array}{c}\text { Super-phosphate, } \\
15 \%\end{array}$ & $\begin{array}{c}\text { Nitrate, } \\
33.5 \%\end{array}$ & Urea, $46.5 \%$ \\
\hline 1 & 7.5 & 50 & 48 & 115.32 & 166.74 & 120.18 \\
\hline 2 & 7.5 & 22 & 48 & 32.38 & 60.94 & 40.16 \\
\hline 3 & 5.0 & 22 & 32 & 120.16 & 168.16 & 114.84 \\
\hline 4 & 5.5 & 36 & 48 & 61.42 & 84.19 & 53.84 \\
\hline 5 & 7.5 & 22 & 16 & 73.14 & 110.14 & 80.18 \\
\hline 6 & 10 & 36 & 48 & 102.14 & 145.9 & 105.6 \\
\hline 7 & 5.0 & 50 & 32 & 53.14 & 77.94 & 71.16 \\
\hline 8 & 10 & 22 & 32 & 99.36 & 142.13 & 100.27 \\
\hline 9 & 10 & 36 & 16 & 42.42 & 72.46 & 58.94 \\
\hline 10 & 10 & 50 & 32 & 86.15 & 126.84 & 83.14 \\
\hline 11 & 5.5 & 36 & 16 & 73.14 & 110.14 & 80.18 \\
\hline 12 & 7.5 & 36 & 32 & 62.84 & 124.36 & 98.17 \\
\hline 13 & 7.5 & 36 & 32 & 84.16 & 150.3 & 18.37 \\
\hline 14 & 7.5 & 36 & 32 & 85.38 & 118.96 & 88.94 \\
\hline 15 & 7.5 & 50 & 16 & 73.14 & 11.14 & 80.18 \\
\hline
\end{tabular}

The following Response Surface Regression functions with transformed-dependent variables for fertilizer application rates " $A_{R}$, $\mathrm{kg} / \mathrm{fed}$ " were developed using three different types of fertilizers, namely, supper phosphate "15\%", Nitrate "33.5\%" and Urea "46.5\%":$\mathrm{A}_{\mathrm{R}}$, of super phosphate $=73.14+2.08 \mathrm{~A}_{\mathrm{s}}+24.14 \mathrm{~A}_{\mathrm{v}}+7.66 \mathrm{G}_{\mathrm{a}}+26.08 \mathrm{~A}_{\mathrm{s}}^{2}$

$$
\begin{aligned}
& -11.71 \mathrm{~A}_{\mathrm{v}}{ }^{2}-5.97 \mathrm{G}_{\mathrm{a}}{ }^{2}-0.86 \mathrm{~A}_{\mathrm{s}} \cdot \mathrm{A}_{\mathrm{v}}+0.50 \mathrm{~A}_{\mathrm{s}} \cdot \mathrm{G}_{\mathrm{a}}+2.82 \mathrm{~A}_{\mathrm{v}} \cdot \mathrm{G}_{\mathrm{a}} \\
& \mathrm{R}-\mathrm{Sq}=96.54 \%(5)
\end{aligned}
$$


$A_{R}$, of Nitrate, $33.5 \%=77.14+2.41 A_{s}+39.25 A_{v}+9.96 G_{a}+39.28 A_{s}^{2}$ $+7.83 \mathrm{~A}_{\mathrm{v}}^{2}+17.04 \mathrm{G}_{\mathrm{a}}^{2}-1.21 \mathrm{~A}_{\mathrm{s}} \cdot \mathrm{A}_{\mathrm{v}}-1.03 \mathrm{~A}_{\mathrm{s}} \cdot \mathrm{G}_{\mathrm{a}}+3.61 \mathrm{~A}_{\mathrm{v}}$. $\mathrm{G}_{\mathrm{a}} \quad \mathrm{R}-\mathrm{Sq}=74.74 \%$

$A_{R}$, of Urea, $46.5 \%=80.18-2.88 A_{s}+28.43 A_{v}+9.10 G_{a}+12.71 A_{s}^{2}-$ $2.88 \mathrm{~A}_{\mathrm{v}}^{2}+1.61 \mathrm{G}_{\mathrm{a}}^{2}+3.00 \mathrm{~A}_{\mathrm{s}} \cdot \mathrm{A}_{\mathrm{v}}+2.80 \mathrm{~A}_{\mathrm{s}} \cdot \mathrm{G}_{\mathrm{a}}+0.36 \mathrm{~A}_{\mathrm{v}} \cdot \mathrm{G}_{\mathrm{a}}$ $\mathrm{R}-\mathrm{Sq}=99.10 \%$

Where, "As" is the coded auger peripheral speed; $A_{v}$ is auger volumetric capacity; and $\mathrm{G}_{\mathrm{a}}$ is the gate area. The results from estimated regression coefficients for Super phosphate, Nitrate and Urea application rates function are given in table 4.

Equs. (5) to (7) with respect to each independent variable yields the optimum levels. The optimum level of the auger peripheral speed " $\mathrm{A}_{\mathrm{s}}$ ", auger volumetric capacity and gate area for three different fertilizer types are very close and they are in good agreement (table 5). From the equations $(5,6$, and 7$)$, the factor that more effect on the application rate performances is the " $A_{v}$ " which recorded the height significant effect of "F" tests fouled by " $\mathrm{G}_{\mathrm{a}}$ " and " $\mathrm{A}_{\mathrm{s}}$ " parameters. From equations 5-7, the analysis of the response surface as the relationship between the equations factors residual and its percentage, the normal probability plots are plotted in Figs. 4-a, 4-b and 4-c for three types of fertilizer used (Super phosphate, $15 \%$, Nitrate, $33.5 \%$, and Urea, $46.5 \%$ respectively).

Table (4): Estimated Regression Coefficients of $A_{R}$ "kg/fed" for Super phosphate, Nitrate and Urea.

\begin{tabular}{|l|l|l|l|}
\hline Term & $\begin{array}{l}\text { Coef.for Super- } \\
\text { phosphate, 15\% }\end{array}$ & $\begin{array}{l}\text { Coef. for } \\
\text { Nitrate, 33.5\% }\end{array}$ & $\begin{array}{l}\text { Coef. for } \\
\text { Urea, 46.5\% }\end{array}$ \\
\hline Constant & 133.792 & 425.588 & 140.992 \\
\hline Auger speed, m/s & -61.2969 & -91.2420 & -36.9731 \\
\hline Auger volume, $\mathrm{cm}^{\wedge} 3$ & 5.81056 & -0.331492 & 2.39773 \\
\hline Gate area, $\mathrm{cm}^{\wedge} 2$ & 1.42452 & -4.02352 & -0.416038 \\
\hline Auger speed, m/s* Auger speed, m/s & 4.17420 & 6.28480 & 2.03340 \\
\hline $\begin{array}{l}\text { Auger volume,cm^3*Auger volume, } \\
\mathrm{cm}^{\wedge} 3\end{array}$ & -0.0597895 & 0.0399872 & -0.0147130 \\
\hline Gate area, $\mathrm{cm}^{\wedge} 2^{*} \mathrm{Gate}$ area, $\mathrm{cm}^{\wedge} 2$ & -0.0233252 & 0.0665527 & 0.00630371 \\
\hline $\begin{array}{l}\text { Auger speed,m/s*Auger volume, } \\
\mathrm{cm}^{\wedge} 3\end{array}$ & -0.0245714 & -0.0345000 & 0.0855714 \\
\hline Auger speed,m/s*Gate area, $\mathrm{cm}^{\wedge} 2$ & 0.0125625 & -0.0256875 & 0.0699375 \\
\hline $\begin{array}{l}\text { Auger volume, cm^3*Gate area, } \\
\mathrm{cm}^{\wedge} 2\end{array}$ & 0.0125893 & 0.0160937 & 0.00158482 \\
\hline
\end{tabular}


Table (5): The optimum level of the variable on the fertilizer application rates

\begin{tabular}{|l|c|c|c|}
\hline \multicolumn{1}{|c|}{ Fertilizer types } & $\begin{array}{c}\text { Super phosphate, } \\
15 \%\end{array}$ & Nitrate, 33.5\% & Urea, 46.5\% \\
\hline Auger volume & $\mathrm{A}_{\mathrm{v}}=45 \mathrm{~cm}^{\wedge} 3$ & $\mathrm{~A}_{\mathrm{v}}=50 \mathrm{~cm}^{\wedge} 3$ & $\mathrm{~A}_{\mathrm{v}}=50 \mathrm{~cm}^{\wedge} 3$ \\
\hline Gate aria & $\mathrm{G}_{\mathrm{a}}=40 \mathrm{~cm}^{\wedge} 2$ & $\mathrm{G}_{\mathrm{a}}=50 \mathrm{~cm}^{\wedge} 2$ & $\mathrm{G}_{\mathrm{a}}=50 \mathrm{~cm}^{\wedge} 2$ \\
\hline Auger speed & $\mathrm{A}_{\mathrm{s}}=5.0 \mathrm{~m} / \mathrm{s}$ & $\mathrm{A}_{\mathrm{s}}=10.0 \mathrm{~m} / \mathrm{s}$ & $\mathrm{A}_{\mathrm{s}}=5.0 \mathrm{~m} / \mathrm{s}$ \\
\hline
\end{tabular}

While the histogram in Figs, 5-a, 5-b and 5-c illustrate the frequency of equations residual. For the Figs. 4-a and 4-c, the percentage of equation residuals are distributed around the equation functions while they were concentrated about zero residual as shown in Fig. 4-b. Also, the frequency plots (Figs. 5-a, 5-b and 5-c) gave the same of the above trend.
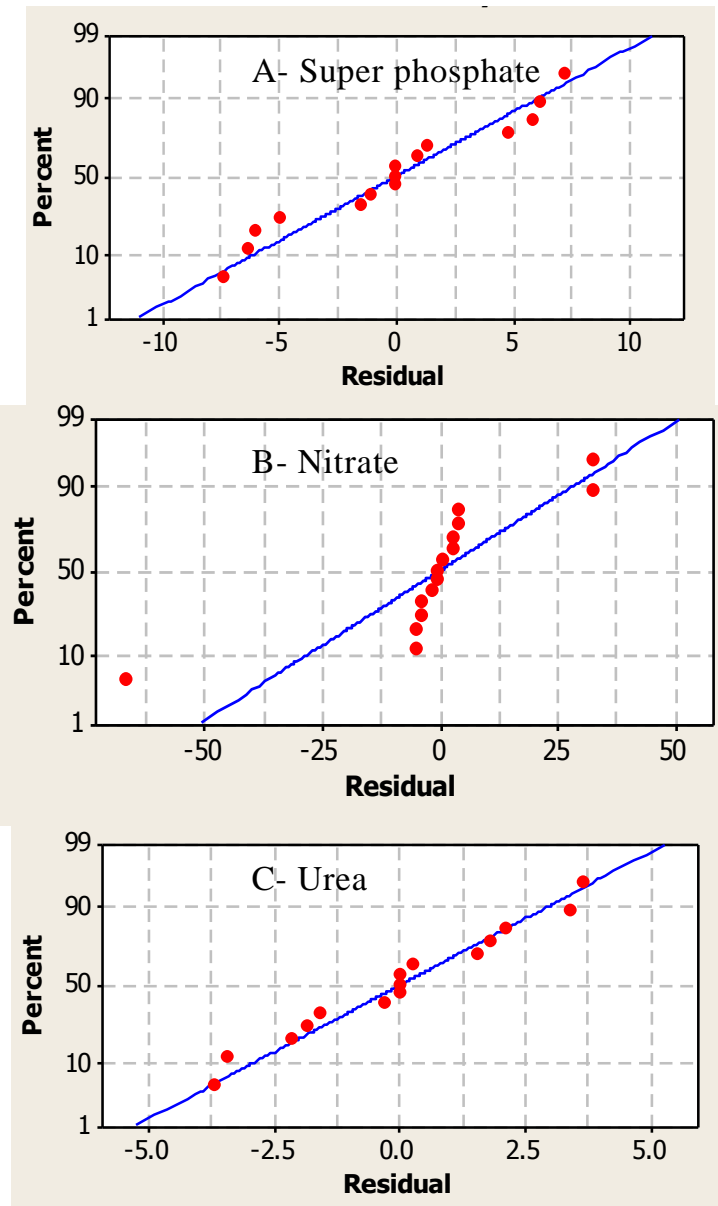

Fig. 4: The percentage of equations factors residual. 

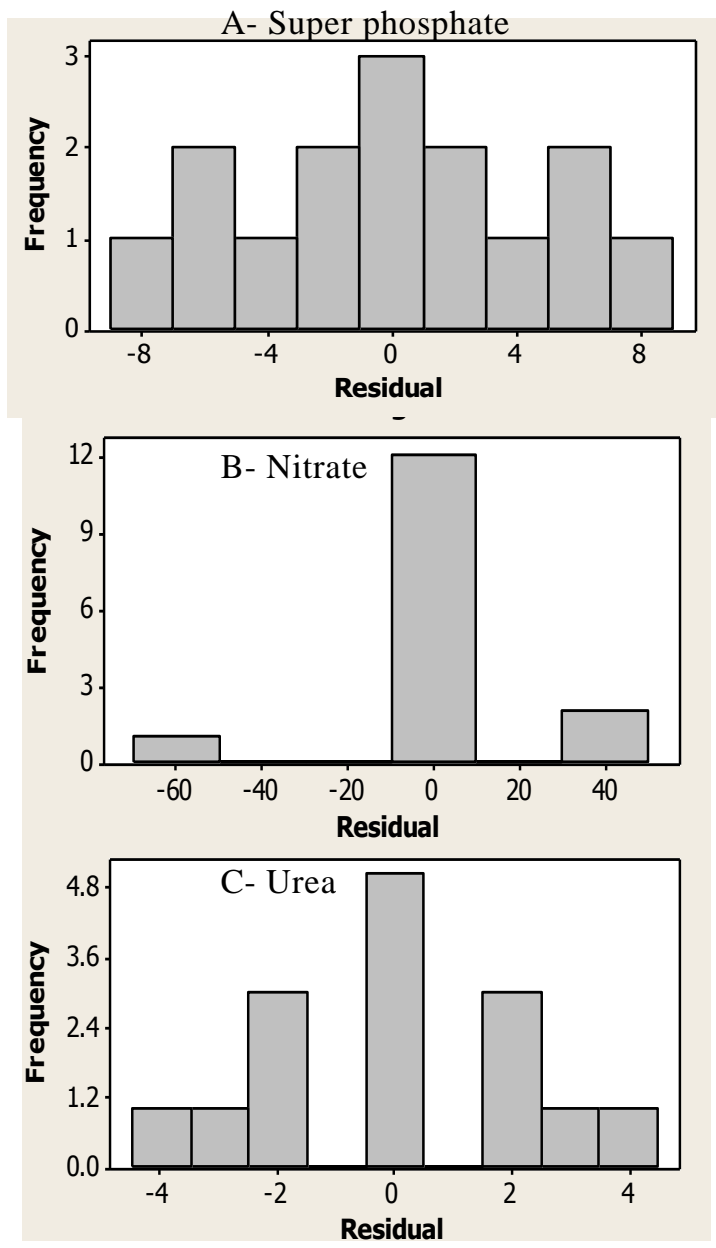

Fig. 5: The frequency of equations factors residual.

Graphical view of some response surfaces as drawn using surface plot are depicted in Figs. "6 and 7". A surface plot in Figs. "6-a, 6-b and 6$c$ " displays a three-dimensional view (application rate in " $z$ " axis, auger speed in " $x$ " axis and gate area in " $y$ " axis) that may provide a clearer picture of the response surface based on a model equation.

Also, the response surface for relationship between auger speed in " $x$ " axis and auger volume in " $y$ " axis on the application rate are depicted in Figs. 7-a, 7-b and 7-c for Super phosphate, Nitrate and Urea respectively. 

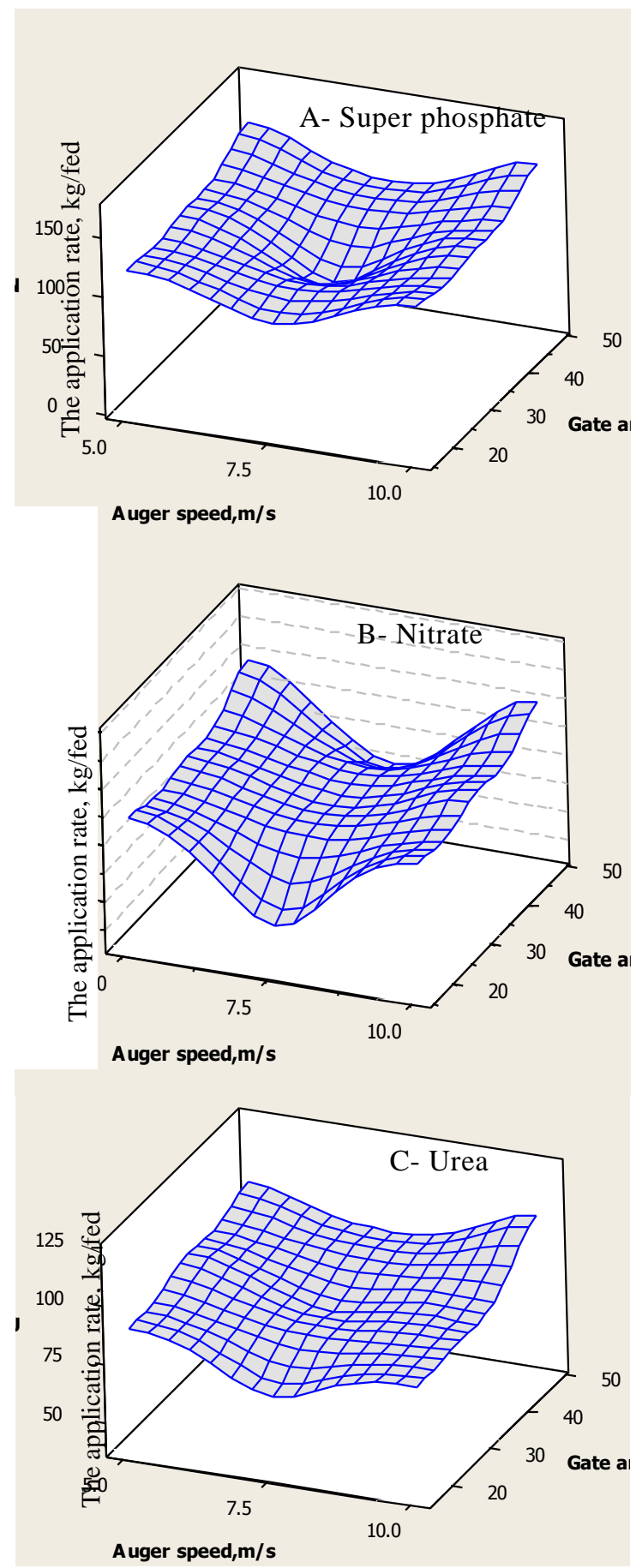

Fig. 6: the surface plot of application rate Vs gate area and auger speed 
A- Super phosphate
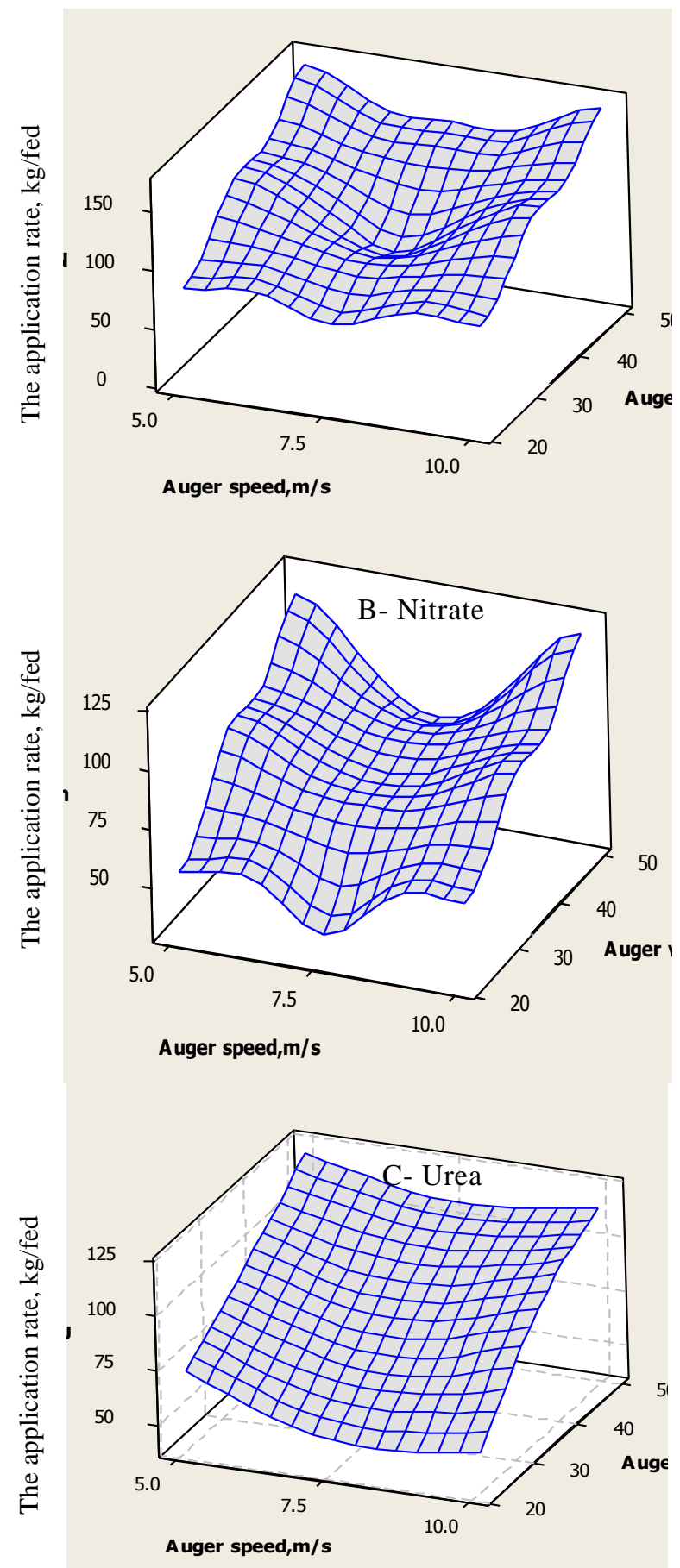

Fig. 7: The surface plot of application rate Vs auger volume and auger speed. 


\section{2- The volumetric efficiency " $\eta_{v}$ "}

The effects of auger shaft speed, auger volume, and orifice gate area for different fertilizer types on the volumetric efficiency illustrate in figures (8), (9) and (10). The general trend of this relationship is that the volumetric efficiency increases directly with increasing the auger speed up to $5.5 \mathrm{~m} / \mathrm{s}$ for most treatments. Beyond this value, the volumetric efficiency decreased. This trend may be attributed to after this point; the centrifugal force restricts the flow of fertilizers.

Generally, the results indicate that the highest value of the volumetric efficiency was $86 \%$. It was obtained when the orifice gate was adjusted at cross section area of $48 \mathrm{~cm}^{2}$, auger volume capacity of $50 \mathrm{~cm}^{3}$, and auger shaft speed of $4.44 \mathrm{~m} / \mathrm{s}$ for spherical shaped particles (Urea) as shown in Fig (10). While, the lowest value is $28 \%$ at the sequence conditions of gate area of $16 \mathrm{~cm}^{2}$, auger volume of $22 \mathrm{~cm}^{3}$ and auger speed of $8.33 \mathrm{~m} / \mathrm{s}$, for powdered shaped particles (Super phosphate) as shown in Fig.(8). Meanwhile, at sing Nitrate, the volumetric efficiency of fertilizer " $\eta_{\mathrm{v}} \%$ " were $70 \%, 81 \%$ and $86 \%$, at $16 ; 32$ and $48 \mathrm{~cm}^{2}$ gate areas, respectively for auger volume of $22 \mathrm{~cm}^{3}$. While, the volumetric efficiency were $75 \%$; $83 \%$ and $87 \%$ for auger volume of $36 \mathrm{~cm}^{3}$ and were $73 \% ; 80 \%$ and $85 \%$ for auger volume of $50 \mathrm{~cm}^{3}$ under the same condition (Fig. 9).

The effect of auger shaft speed on volumetric efficiency was analyzed using the regression type of power analysis. The results of analysis showed that, the relationship between the studied variables could be described as follows:

$$
\eta_{\mathrm{v}}=-\mathrm{k} \mathrm{N}^{2}+\mathrm{bN}+\mathrm{n}
$$

Where

$\eta_{\mathrm{v}}$ : volumetric efficiency, $(\%)$;

$\mathrm{N}$ : auger shaft speed, $(\mathrm{m} / \mathrm{s})$;

$\mathrm{k}, \mathrm{b}$ and $\mathrm{n}$ : coefficient constants.

The values of the constants $k, b$ and $n$ are presented in Table (3). The statistically analysis of SAS is not a significance difference between the levels of $(2.77$ and $9.44 \mathrm{~m} / \mathrm{s}),(3.33$ and $2.77 \mathrm{~m} / \mathrm{s}),(3.88$ and $4.44 \mathrm{~m} / \mathrm{s})$, $(5.55$ and $4.99 \mathrm{~m} / \mathrm{s})$ and $(11.66,8.33$ and $8.88 \mathrm{~m} / \mathrm{s})$ on the volumetric efficiency. 
Auger volume, $22 \mathrm{~cm}^{3}$
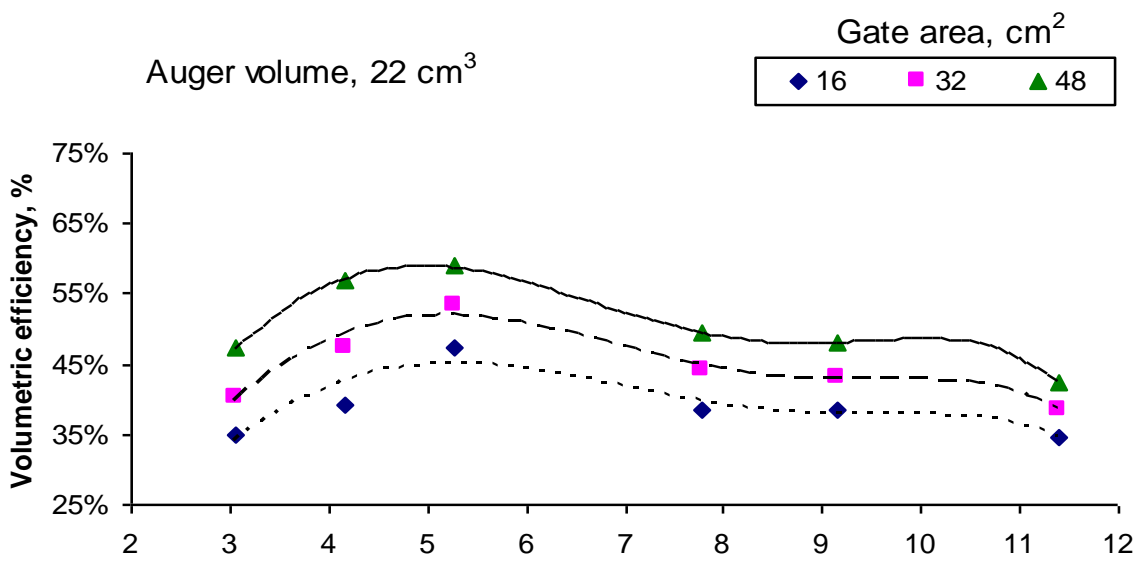

Auger volume, $36 \mathrm{~cm}^{3}$

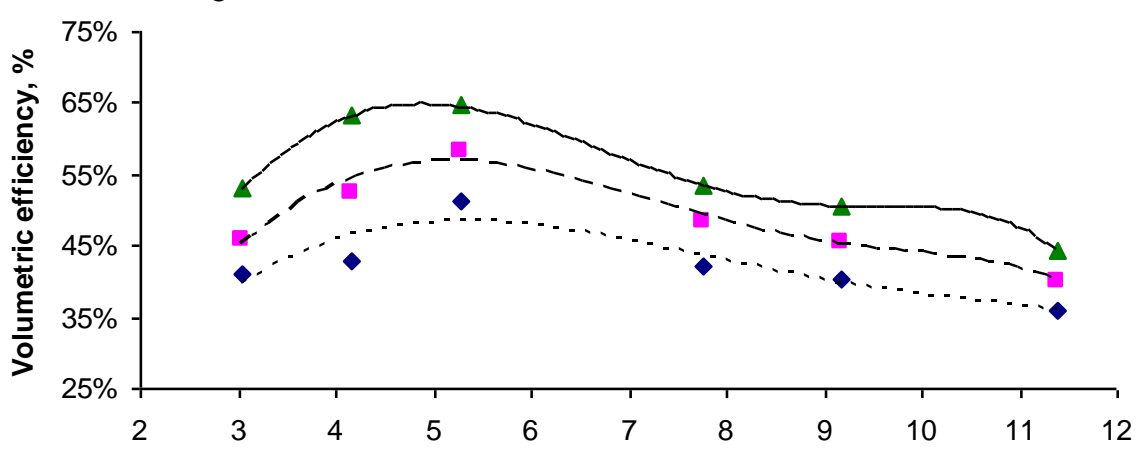

Auger volume, $50 \mathrm{~cm}^{3}$

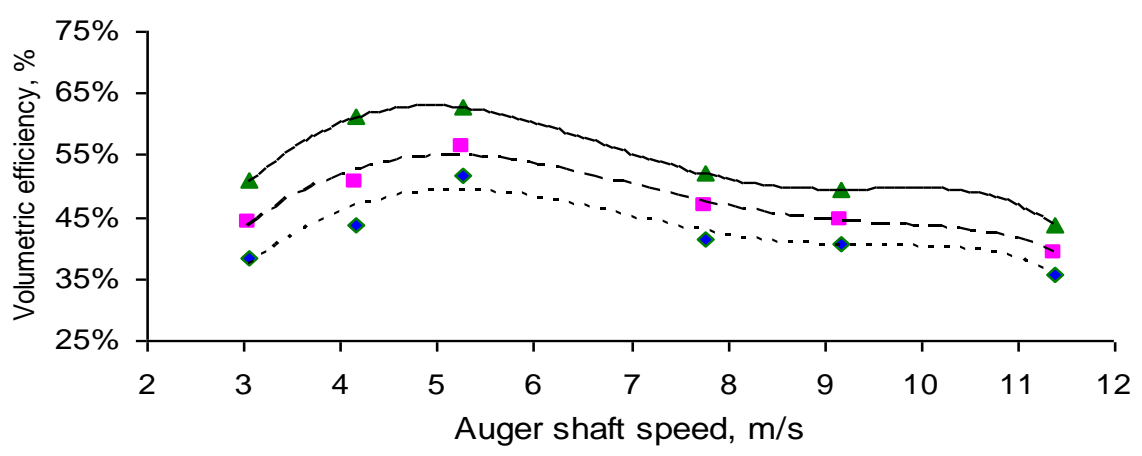

Fig. 8: Effect of auger shaft speed on volumetric efficiency at Super phosphate 

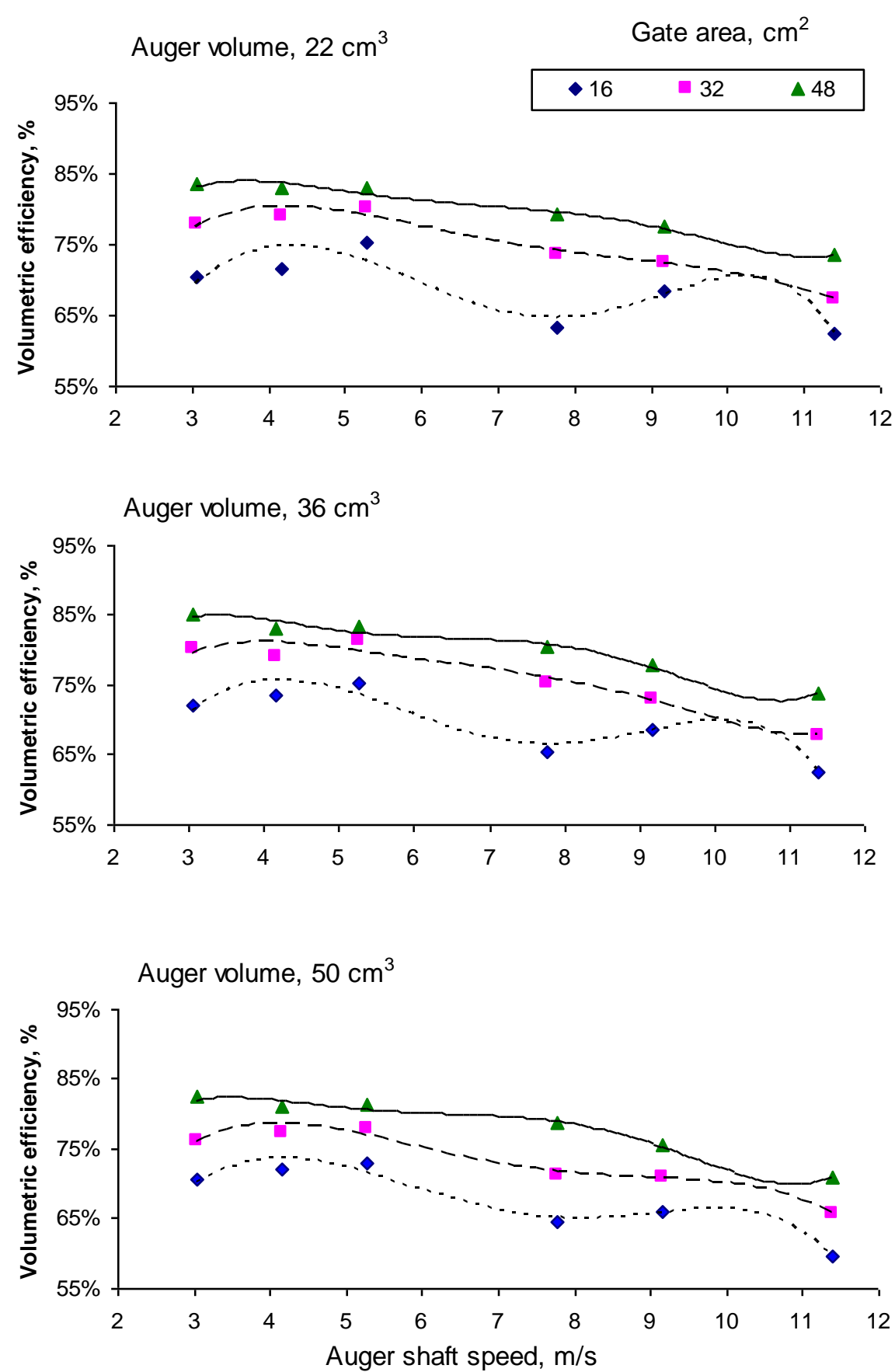

Fig. 9: Effect of auger shaft speed on volumetric efficiency at Nitrate. 


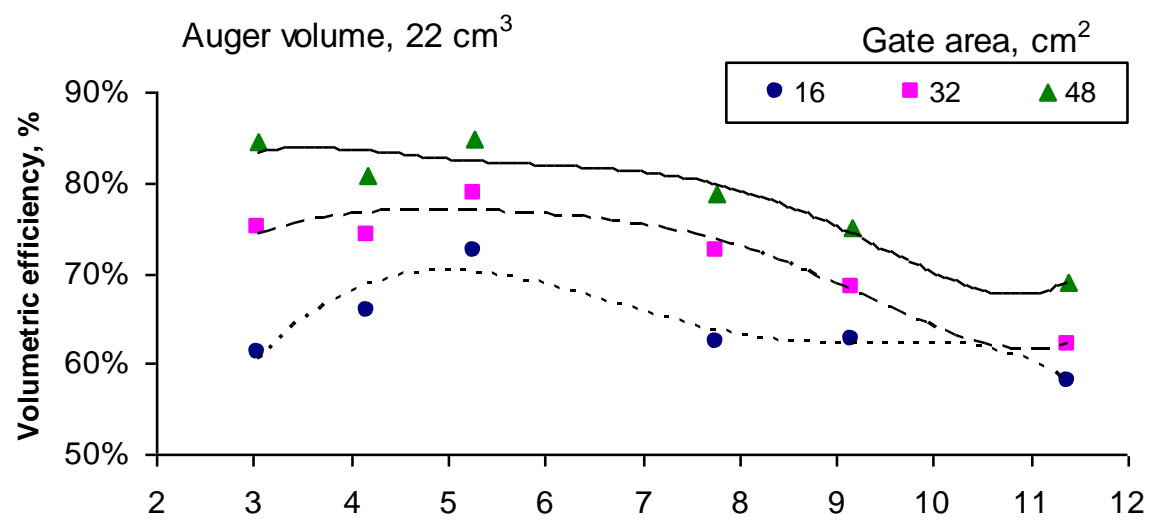

Auger volume, $36 \mathrm{~cm}^{3}$

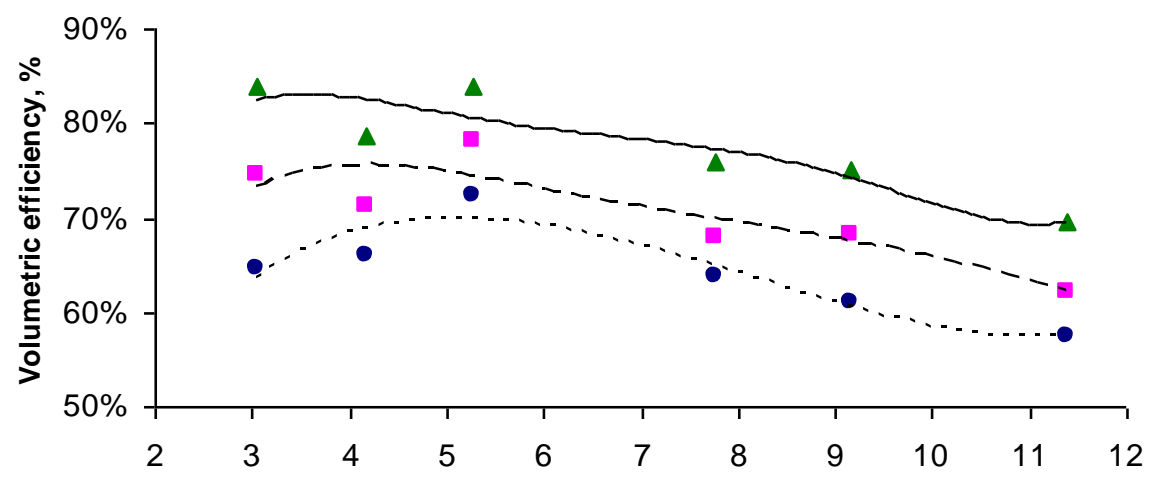

Auger volume, $50 \mathrm{~cm}^{3}$

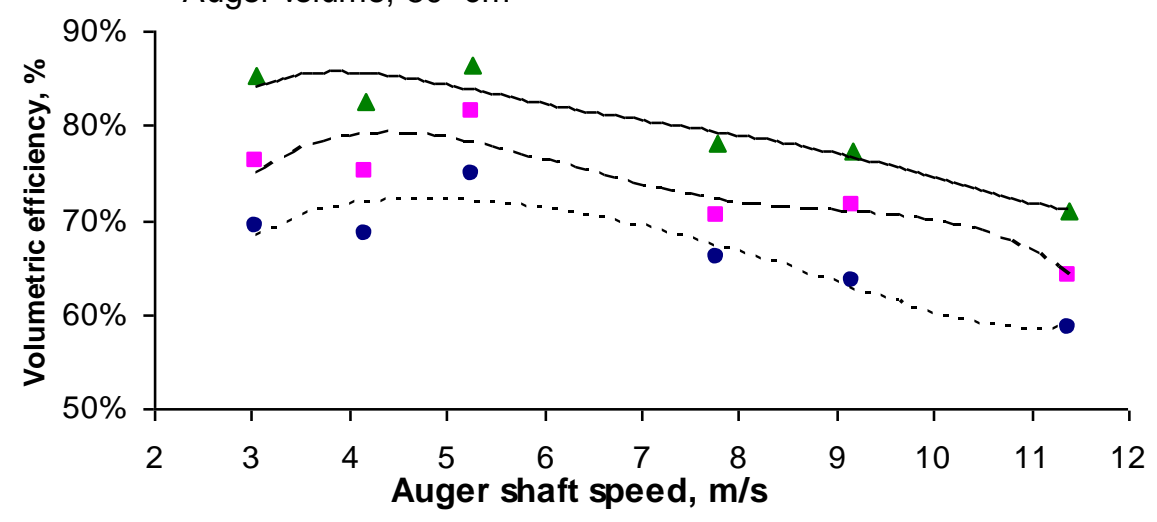

Fig. 10: Effect of auger shaft speed on volumetric efficiency at Urea. 
Table 3: Values of constants ( $\mathrm{k}, \mathrm{b}$ and $\mathrm{n}$ ) of equation (8):

\begin{tabular}{|l|c|c|c|c|c|}
\hline Fertilizer name & Bulk density, $\mathrm{g} / \mathrm{cm}^{3}$ & $\mathrm{k}$ & $\mathrm{b}$ & $\mathrm{n}$ & $\mathrm{R}^{2}$ \\
\hline Urea & 0.685 & 0.0019 & 0.0131 & 0.7341 & 0.611 \\
\hline Nitrate & 0.913 & 0.0021 & 0.0179 & 0.7428 & 0.8919 \\
\hline Super-phosphate & 0.995 & 0.0009 & 0.0012 & 0.4941 & 0.2032 \\
\hline
\end{tabular}

\section{CONCLUSIONS}

The conclusions of this paper are summarized as follow:

1. The highest value of discharge rate is $2660 \mathrm{~g} / \mathrm{min}$, which is obtained when the orifice gate is adjusted at cross sectional area of $48 \mathrm{~cm}^{2}$, auger volume of $50.66 \mathrm{~cm}^{3}$ and the rotational speed of feeding shaft of $11.6 \mathrm{~m} / \mathrm{s}$ for Urea. While the lowest value was $190 \mathrm{~g} / \mathrm{min}$ at the same condition of $2.7 \mathrm{~m} / \mathrm{s}$, auger volume of $24.27 \mathrm{~cm}^{3}$ and gate area of $16 \mathrm{~cm}^{2}$ for super Phosphate.

2. Increasing the gate area from 16 to $48 \mathrm{~cm}^{2}$, the volumetric efficiency increases from $64.9 \%$ to $79.0 \%$ at bulk density of $0.685 \mathrm{~g} / \mathrm{cm}^{3}$. Also, it increases from $68.6 \%$ to $79.7 \%$ and from $39.4 \%$ to 51.2 $\%$, with bulk density of 0.913 and $0.995 \mathrm{~g} / \mathrm{cm}^{3}$ respectively.

\section{REFERENCES}

Fouda O. A. (2007). A combined unit to prepare the bed of some vegetable crops. Ph.D. Thesis, Agric. Eng. Dept., Fac. of Agric., Mansoura Univ. Egypt.

Ismail, Z. E. (2009). Soil response to tillage treatments. Agricultural Mechanization In Asia, Africa and Latin America (AMA). Vol. 40, No. 4 autumn: 9-14.

Ismail, Z. E. (2007). Applied and theoretical fundamentals in seed-bed preparation implements. Part one, $2^{\text {nd }}$ Ed. Published at Mansoura University.

Kaplan, J.; J. Chaplin; P.C. Robert (ed.); R.H. Rust (ed.) and W.E. Larson (1999). Unevenness of fertilizer distribution and determination of the application rate. Biosystems and Agr. Eng. Dept., Univ. of Minnesota, St. Paul, Minnesota, USA. Proc. of the $4^{\text {th }}$ Int. Conf. of Prec. Agr., St. Paul, Minnesota, USA, 19-22 July 1998. Part A and Part B. 943-952. 
Kathleen M.C., N. Y. Kamneva and J. Reminga (2004). Response Surface Methodology. CASOS Technical Report, CMU-ISRI-04136, Carnegie Mellon University, School of Computer Science, ISRI - Institute for Software Research International, CASOS Center for Computational Analysis of Social and Organizational Systems.

Kleijnen, J.P.C. (1998). Experimental Design for Sensitivity Analysis, Optimization, and Validation of Simulation Models. In Handbook of simulation: principles, methodology, advances, applications and practice, ed. J. Banks, 173-223. New York: John Wiley \& Sons.

Neddermeijer, H.G.; G.J van Oortmarssen.; N. Piersma; R. Dekker (2000). A Framework for Response Surface Methodology for Simulation Optimization Models. Proceedings of the 2000 Winter Simulation Conference (edited by J.A. Joines, R.R. Barton, K Kang, and P.A. Fishwick), pp. 129-136.

Lee, W.C.; S. Yusof; N.S.A. Hamid and B.S. Baharin (2006). Optimizing conditions for enzymatic clarification of banana juice using response surface methodology (RSM). Journal of Food Engineering, 73, 55-63.

Liu, F.; H. Jia; C. Zhang; H. Zhang; K. Araya; M. Kudoh and H. Kawabe (1998). Improvement of Planosol Solum. Part 9: Fertilizer distributor for subsoil. Hejiang Agricultural Research Institute, Jiamusi, Heilongjiang, China. J. of Agr. Eng. Res. 71: 3, 213-219.

Persson, K.; J. Bangsgaard and J.V. Stafford (1999). Accuracy of fertiliser distribution for Site Specific Fertilisation. Danish Institute of Agricultural Sciences, Research Centre Bygholm, DK-8700 Horsens, Denmark. Precision agriculture 99, Part 2. Papers presented at the 2nd European Conference on Precision Agriculture, Odense, Denmark, 11-15 July 1999.

Reumers, J.; E. Tijskens and H. Ramon (2003). Experimental characterisation of the tangential and cylindrical fertilizer distribution pattern from a spinning disc: a parameter study. Biosystems Engineering. 86: 3, 327-337. 


\section{William, M. Miller; A. Mold; W. Schumann and J.D. Whitney} (2004). Evaluating variable rate granular fertilizer technologies in Florida citrus. Proc. Fla. State hort. Soc. 117:161-166.

الملخص العربي

تقييم موزع السماد بإستخدام طريقة إستجابة التأثير السطى المئي

$$
\text { أ.د/ زكريا إبراهيم إسماعيل }
$$

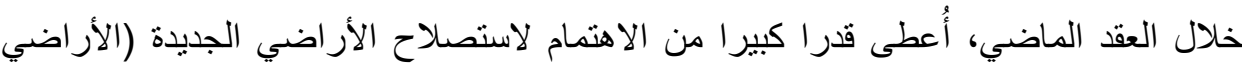

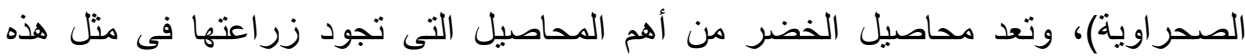

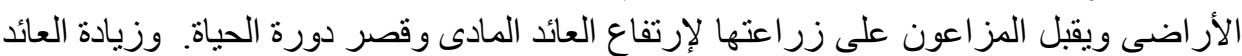

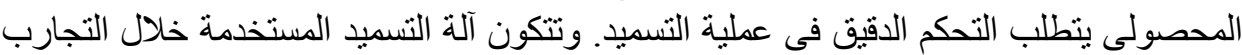

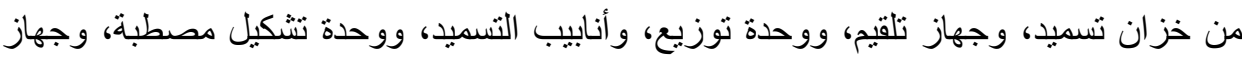

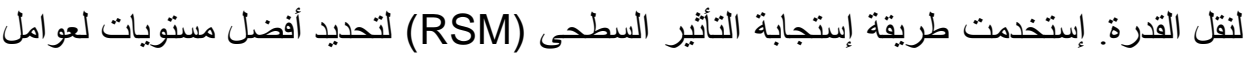

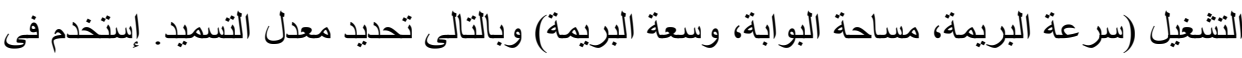

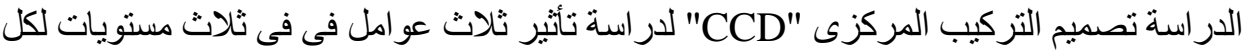

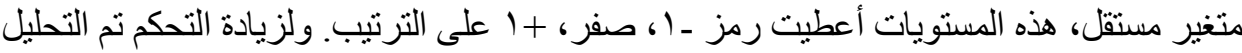

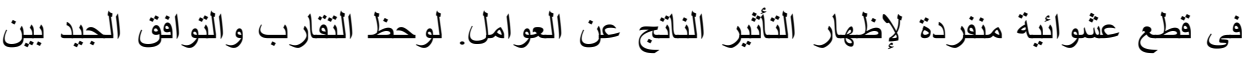

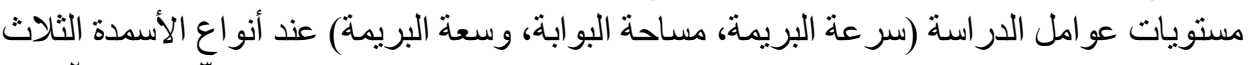

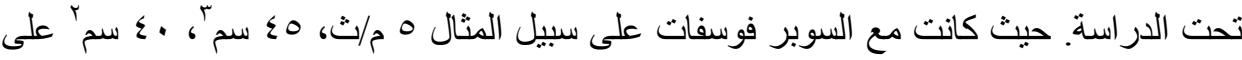

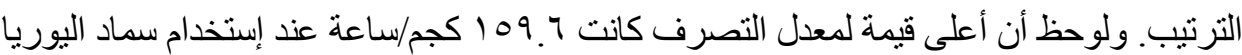

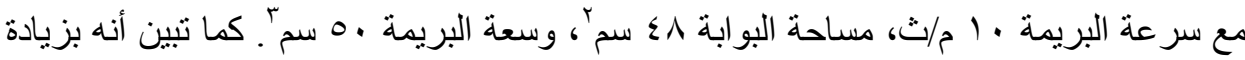

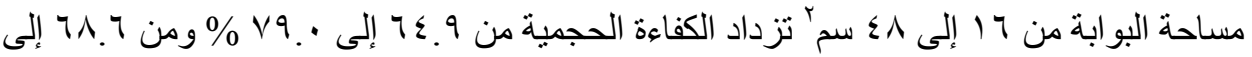

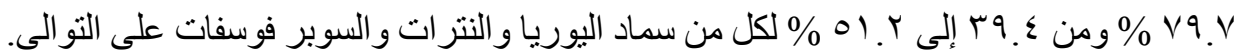

* أستاذ تكنولوجيا القوى والآلات ورئيس قسم الهندة الزراعية ـ كلية الزراعة - جامعة المنصورة 